\title{
Rollerblading and skateboarding injuries in children in northeast England
}

\author{
I Hassan, B J Dorani
}

\begin{abstract}
Objectives-To establish the demographic profile and injury characteristics of children presenting with rollerblading or skateboarding associated injuries. This study also examines the circumstances leading to these injuries with a view to suggesting preventive measures.
\end{abstract}

Methods-A prospective study using a proforma to collect data from each child presenting with rollerblading or skateboarding related injuries. Injury details were obtained from clinical and radiological records. The injury severity score (ISS) was calculated for each child and statistical analysis was done using $\chi^{2}$.

Results-Eighty one children presented with rollerblading associated injuries accounting for $7 \%$ of childhood injuries seen during the eight month study period. The mean age was 10.3 years and sex distribution was equal. Soft tissue injuries accounted for $51 \%$ and fractures for $49 \%$ of the injuries. Wrist fractures alone accounted for $86 \%$ of all fractures seen. Seventy per cent of soft tissue injuries involved the upper limb. The overall mean ISS was 3.0 with a range from 1 to 9 . Injury was attributed to fall secondary to loss of control or collision with an obstacle while rollerblading in the majority of children. Injury occurred while rollerblading in residential or public places in $99 \%$ of the children. In contrast skateboarding related injuries were much rarer and caused soft tissue injuries only.

Conclusion-This study has revealed a higher incidence of rollerblading injuries than previously suspected. Effective management strategies should include not only the treatment of these injuries but also attention to their causes and prevention.

(F Accid Emerg Med 1999;16:348-350)

Keywords: rollerblading associated injuries; skateboarding associated injuries; children; prevention

Accident and

Emergency

Department, Queen

Elizabeth Hospital,

Gateshead, Tyne and

Wear NE6 6SX

I Hassan

B J Dorani

Correspondences to:

Mr Hassan, Staff Grade in

Accident and Emergency

Medicine.

Accepted 29 April 1999 popularity of rollerblading. ${ }^{5-9}$ Since its introduction in the 1980 s the popularity of rollerblading has been increasing rapidly and currently it is the fastest growing recreational sport in the United States. ${ }^{56}$ More recently a similar trend of increasing popularity of rollerblading as a recreational and fashionable sport has also been seen in the UK. Rollerbladers are now commonly seen in town and city streets and parks in Britain. Injuries associated with rollerblading are increasingly being seen in British accident and emergency (A\&E) departments. ${ }^{10-12}$

Although the American experience with rollerblading associated injuries is fairly extensively reported, ${ }^{5-10}$ British experience remains somewhat limited. Previous reports from the UK have been confined to patients with bony injuries requiring orthopaedic consultation only, ${ }^{10}$ children presenting to a specialist inner city children's hospital only, ${ }^{11}$ or patients of all age groups ${ }^{12}$ seen in a district general hospital. Most previous reports indicate that rollerblading injuries are mainly a problem of childhood. ${ }^{6111314}$ This prospective study therefore aims to establish the size and profile of this rapidly emerging problem encountered in children in a busy British district general hospital with a predominantly urban catchment population. This paper adds to the growing body of information on this emerging problem about which little has been written so far. Such information can be used effectively for planning of local services and preventive measures.

\section{Methods}

This prospective study was undertaken in the $A \& E$ department of a busy district general hospital in northeast England. Data were collected during an eight month study period between September 1997 and April 1998. A proforma was designed to collect data from each child who presented to the $A \& E$ department with rollerblading or skateboarding associated injuries. Data collected included age, sex, duration of injury, place of occurrence of injury, the mechanism of injury, and the type of injury sustained. The place of occurrence of injury was classified as residential area, school, public park or playground, main road, pavement/footpath, public sporting place, or others (specified). The mechanism of injury was established by obtaining specific details of the circumstances that led to the injury for each child. Details of the actual injury sustained were obtained from both clinical and radiological records. The injury severity score (ISS) was calculated for each child. Statistical analysis was done using $\chi^{2}$ and considered significant at $\mathrm{p}<0.05$. 
Table 1 Anatomical distribution of soft tissue injuries (41 children)

\begin{tabular}{lll}
\hline Soft tissue injury & Anatomic location & $\begin{array}{l}\text { No (\%) of } \\
\text { injuries }\end{array}$ \\
\hline Sprains & Wrist & $9(19.0)$ \\
& Elbow & $7(15.0)$ \\
Contusions & Lower extremity & $3(6.3)$ \\
& Wrist & $4(8.5)$ \\
& Elbow & $4(8.5)$ \\
& Forearm & $2(4.2)$ \\
Lacerations & Hand & $1(2.1)$ \\
& Face & $1(2.1)$ \\
Abrasions & Face and neck & $5(10.6)$ \\
& Arm & $1(2.1)$ \\
& Upper extremity & $2(4.2)$ \\
& Chest & $1(2.1)$ \\
Minor head injury & Face & $1(2.1)$ \\
Total injuries & Head & $1(2.1)$ \\
& & $5(10.6)$ \\
\hline
\end{tabular}

Table 2 Anatomical distribution of fractures

\begin{tabular}{lc}
\hline Site of fractures & $\begin{array}{l}\text { No (\%) of } \\
\text { children }\end{array}$ \\
\hline Distal radius only & $22(55.0)$ \\
Distal radius and distal ulna & $12(30.0)$ \\
Shaft of radius & $1(2.5)$ \\
Shafts of radius and ulna & $1(2.5)$ \\
Phalanges (finger) & $3(7.5)$ \\
Medial malleolus & $1(2.5)$ \\
Total & $40(100)$ \\
\hline
\end{tabular}

\section{Results}

Eighty one children were seen with rollerblading associated injuries. This represented just over $1 \%$ of the 7566 children seen in the department and $7 \%$ of childhood injuries seen during the eight month study period. The mean (SD) age was 10.3 (2.3) years, although the ages ranged from 5 to 15 years. Males slightly outnumbered females with a ratio of 1.1:1.

The overall mean (SD) ISS was 3 (2) with a range of 1 to 9 . The incidence of soft tissue injuries was $51 \%(n=41)$ and fractures $49 \%$ $(n=40)$.

Of the 41 children with soft tissue injuries, the overall mean (SD) age was 10 (2.2) years. Although males tended to be older (mean (SD) age 11(2.0) years) compared with females (9

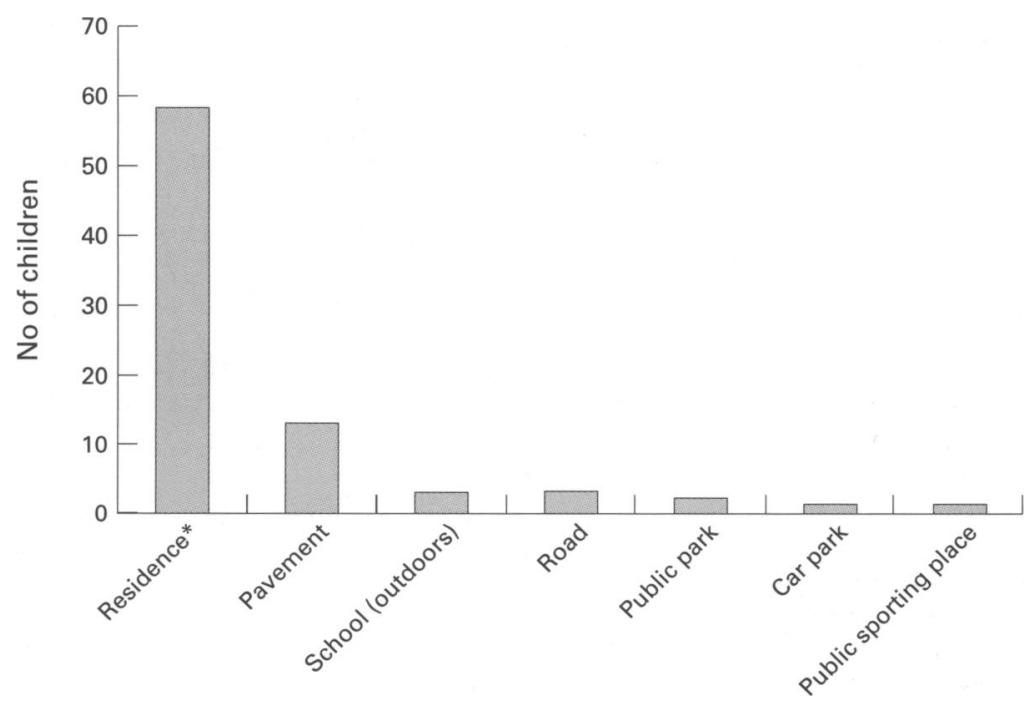

Figure 1 Place of injury $(n=81)$. ${ }^{\star}$ Residence = gardens, driveways, streets, and back lanes in the vicinity of the child's home.
(2.0) years), the sex distribution of this group was almost equal. There were 47 soft tissue injuries among these 41 children. More than two thirds of the soft tissue injuries involved the upper extremity and joint sprains accounted for $40 \%$ the injuries. The mean ISS for this group was 1 (see table 1).

The 40 children with fractures did not differ in age and sex composition from those with soft tissue injuries. In this group the mean (SD) ISS was 4 (1) but ranged from 1 to 9. There were 53 separate fractures in the 40 children and significantly the upper limb was involved in all but one injury. Furthermore fractures at or around the wrist alone accounted for $86 \%$ of the total (see table 2 ).

Overall $76(92 \%)$ children were injured due to a fall while rollerblading. The majority $(n=56)$ of the falls were simply attributed to loss of balance or loss of control. Other causes of fall included attempts to avoid collision with fixed or moving obstacles such as walls, lamp posts, moving motor vehicles, or fellow rollerbladers. More unusual mechanisms of injury included one child being struck by a plastic object and another spontaneously twisting the ankle while rollerblading. Another child developed a painful ankle "spontaneously" immediately after rollerblading.

The accident that caused the rollerblading injury occurred on driveways and back lanes in residential areas, roads, and other public areas in $80(99 \%)$ of the children. Only one of the injuries occurred in a designated sporting area (see fig 1).

The incidence of rollerblading associated injuries in the late summer and winter months was relatively low with fewer than one third of the children presenting in the first five months (September to January) of the study. Thereafter, a sharp rise in the incidence of rollerblading associated injuries was noted with the onset of spring.

Interestingly, only 16 children were seen with skateboarding injuries; this represents only $0.2 \%$ of children attending the $A \& E$ department during this study period. Their ages ranged from 4 to 15 years with a mean (SD) of 10 (2.6) years (there were 11 males aged 9.4 (3.0) and five females aged $11.2(0.9)$ years). All had soft tissue injuries only and the upper limb alone was involved in over two thirds of the children. The accident leading to the injury included falls in 11 children. The skateboard ran over the finger in three children. One child dropped his skateboard on his toe and another child tripped while skateboarding. The accident that led to the injury occurred while skateboarding outdoors on driveways near the child's home in 10 instances and in public parks in three. The accident occurred indoors in two patients and on the pavement in one.

\section{Discussion}

Rollerblading is an increasingly popular recreational sport in the UK in children and young adults. Consequently, rollerblading associated injuries are being seen more frequently in British $A \& E$ departments. ${ }^{10-12}$ Published 
British data on rollerblading associated injuries is relatively scarce, although the American experience is well documented. ${ }^{5-10}$ Previous reports from the UK have examined patients of all age groups requiring admission for bony injuries ${ }^{10}$ general A\&E populations of all age groups, ${ }^{12}$ or patients from a specialist inner city children's A\&E department. ${ }^{11}$ To plan an effective local action aimed at making rollerblading safer we need to size and characterise our local experience. This prospective study reports the experience of the A\&E department of a British district general hospital with rollerblading associated injuries in children. This paper adds to the growing body of literature on this rapidly emerging significant cause of injuries in children.

Interestingly, this study has shown that rollerblading associated injuries are not uncommon and account for a significant number of injuries seen in children. Although these injuries accounted for just over $1 \%$ of the paediatric emergency workload they accounted for $7 \%$ of paediatric trauma attendance to this department during the study period. The injuries tended to be more common during the warmer months and affected both boys and girls equally. However the injuries predominantly involved girls under and boys over the age of 10 years. This age pattern was consistent for both children with fractures as well as those with soft tissue injuries. The injury pattern showed fractures in $49 \%$ of the children, and both fractures and soft tissue injuries predominantly affected the upper extremity with an overall mean ISS of 3 . The vast majority of fractures involved the wrist and forearm. These findings are not dissimilar to reports of rollerblading associated injuries in children from Scotland, Germany, and Australia. ${ }^{11-14}$ In contrast to the findings of earlier studies, ${ }^{15}{ }^{16}$ we found skateboarding injuries were relatively rare, accounting for just $0.2 \%$ of our paediatric emergency attendances and all were soft tissue injuries predominantly to the upper limb.

The majority of rollerblading injuries occurred in driveways, back lanes, pavements, and roads around residential areas. These areas pose potential risks to rollerbladers in the form of obstacles such as motor vehicles, lamp posts, and walls. Furthermore falling rollerbladers are more likely to land on hard surfaces making them susceptible to sustain more serious injuries. Rollerblading in these public areas also pose a risk to other road users. The first reported British rollerblading associated death resulted from the collision of a rollerblader with a cyclist in a busy public park resulting in the death of the cyclist in $1996 .^{10}$

Both for their own safety and for the safety of others, serious consideration must be given to restricting rollerbladers from using public areas. Other safety measures may include training in rollerblade safety, as well as provision of local designated rollerblading areas with suitable firm tracks and soft adjacent surfaces to minimise the risk of injures to falling rollerbladers. In addition to the provision of designated rollerblading areas, this study would also support the need for a rollerblading safety campaign. Children of susceptible age groups, as well as their parents, can be reached by focusing any such campaigns at middle and high schools.

This study has demonstrated the vulnerability of the wrist to both soft tissue injuries and particularly fractures. It would be tempting to suggest that the use of protective equipment may reduce the risk of these injuries. However, opinions differ about the effectiveness of protective equipment in preventing such injuries. $^{781017}$ Even a large population based study, which suggested that training in rollerblading and the use of protective equipment reduces the risk of injury, could not offer definitive proof in support. ${ }^{18}$ Further prospective population based studies may clarify the role of protective equipment in reducing the severity of rollerblading associated injuries.

In conclusion, this study has revealed a higher incidence of rollerblading associated injuries than previously suspected. We suggest the provision of rollerblading parks and rollerblading safety education campaigns to make rollerblading safer for children. Emergency physicians need to be alert to identify any unusual or evolving injury mechanisms or causes of morbidity to patients. Effective management strategies should include not only the treatment of these injuries but also attention to the causes and prevention.

The authors gratefully acknowledge the nursing and medical staff of the A\&E Department of the Queen Elizabeth Hospital, Gateshead for their valuable assistance with data collection. A special thank you also to Professor S Jarvis and Dr Liz Towner, Department of Community Child Health, University of Newcastle upon Tyne for their kind advice.

Conflict of interest: none.

Funding: none.

1 Jarvis S, Towner E, Walsh S. Accidents. In: Botting B, ed. The health of our children: decennial supplement. London: HMSO, 1995: 95-112.

2 Secretary of State for Health. Our healthier nation. A contract for health. London: The Stationery Office, 1998.

Retsky J, Jaffe D, Christoffel K. Skateboarding injuries in children. Am $\mathcal{F}$ Dis Child 1991;145:188-92.

4 Banas MP, Dalldorf PG, Marquardt JD. Skateboard and in-line skate fractures: a report of one summer's experiin-line skate fractures: a report of one

5 Schieber RA, Branche-Dorsey CM, Ryan GW. Comparison Schieber RA, Branche-Dorsey CM, Ryan GW. Comparison of in-line skating injuries with roller skating

6 Mitts KG, Hennrikus WL. In-line skating fractures in chilMitts KG, Hennrikus WL. In-line skating
dren. $\mathcal{F}$ Pediatr Orthop 1996;16:640-3.

dren. F Pediatr Orthop 1996;16:640-3. Calle SC, Eaton RG. Whe

8 Weinberger DG, Selesnick SH. Roller blades falls. $\mathcal{F}$ Trauma 1994;37:500-3.

9 Schieber RA, Branche-Dorsey CM, Ryan GW, et al. Risk factors for injuries from in-line skating and effectiveness of safety gear. N Engl F Med 1996;335:1630-5.

10 Spicer DDM, Mullins MM, Wexler DM. Roller blades: should they carry government warning? Injury 1996;27: 401-3.

11 McGarth D, Beattie TF. Rollerblading in children: the Edinburgh experience. F Accid Emerg Med 1996;13:354-5.

12 Quin GI, McCarthy GM, Jones I. Rollerblade injuries and their prevention. $\mathcal{F}$ Accid Emerg Med 1998;15:278.

3 Schimp G, Nores J, Mayj J. In-line skating injuries. Zentralbl Kinderchir 1997;6:109-13.

4 Heller D. Rollerblading injuries. Hazard 1993;15:11-13.

14 Heller D. Rollerblading injuries. Hazard 1993,15:11-13.

16 Limburger I. Skateboard related injury. Hazard 1997;31:3-7. $140-4$.

17 Lewis LM, West O, Standeven J, et al. Do wrist guard protect against fractures? Ann Emerg Med 1997;29:766-9.

18 Jaffe MS, Marcel DO, Dijkers P. A population-based survey of in-line skaters injuries and skating practices. Arch Phys Med Rehabil 1997;78:1352-7. 